\title{
Um estudo sobre práticas e crenças parentais e o desempenho em escrita de crianças
}

\section{A study of parental practices and beliefs and children's writing performance}

\author{
Selma de Cássia Martinelli* \\ Elaine Cristiane Aguena Matsuoka*
}

\begin{abstract}
RESUMO
O objetivo do presente estudo foi avaliar as possíveis relações entre as práticas e crenças parentais e o desempenho em escrita de alunos do ensino fundamental. Também se buscou verificar as relações entre práticas e crenças parentais. Participaram deste estudo 446 alunos, que cursavam do $2^{\circ}$ ao $5^{\circ}$ ano, de ambos os gêneros e seus respectivos pais. A faixa etária dos alunos variou de 7 a 11 anos e dos pais, de 19 a 69 anos. Foram utilizados dois instrumentos nesta pesquisa, um Teste de Avaliação da Escrita (TAE) e um Inventário de Práticas e Crenças Parentais (IPCp). Os resultados revelaram uma correlação significante e positiva $(r=0,223$, $\mathrm{p}<0,01)$, embora de intensidade fraca, entre o desempenho em escrita e as crenças declaradas pelos pais. Ressalta-se a necessidade de continuar investigando estas variáveis, e suas relações, a fim de permitir um aprofundamento dessa discussão.

Palavras-chave: Ensino fundamental. Psicologia familiar. Avaliação escolar.
\end{abstract}

\begin{abstract}
The objective of the present study was to evaluate the possible relationships between parenting practices and beliefs and writing performance of elementary school students. We also sought to verify the relationships between practices and parental beliefs. A total of 446 students from the second to the fifth year of both genders and their respective parents

* Universidade Estadual de Campinas. Campinas, São Paulo, Brasil. E-mail: selmacm@ unicamp.br. ORCID: https://orcid.org/0000-0001-8528-7052. E-mail: laineneck@hotmail.com. ORCID: https://orcid.org/0000-0001-9884-1948
\end{abstract}


participated in this study. The age range of the students ranged from 7 to 11 years and from the parents, from 19 to 69 years. Two instruments were used in this research, a Writing Assessment Test (APR) and an Inventory of Practices and Parental Beliefs (IPCp). The results showed a significant and positive correlation $(r=0,223, p<0,01)$ between the writing performance and the beliefs declared by the parents. It is necessary to continue investigating these variables and their relations in order to allow a deepening of this discussion.

Keywords: Elementary school. Family psychology. School evaluation.

O meio social é uma esfera importante a ser considerada quando se trata de pensar a aprendizagem escolar. Estudos têm sugerido que o contexto familiar em que a criança está inserida pode contribuir de diversas formas para o seu desenvolvimento e aprendizado (SILVA; HASENBALG, 2002). Assim, é possível dizer que, os indivíduos imersos em um contexto familiar, escolar e social que propicie experiências mais variadas e desafiadoras encontram-se em condições mais favorecedoras ao seu desenvolvimento e aprendizado (MARTINELLI; CALIATTO, 2017). Contudo, com as inúmeras transformações ocorridas na sociedade, e nas organizações familiares, vê-se como necessário, conforme apontam Santos, Martinelli e Monteiro (2012), que novos estudos se detenham a olhar para as questões colocadas anteriormente.

A interação entre pais e filhos é vista como importante variável de estudo (BAUMRIND, 1966; DARLING; STEINBERG, 1993; MACCOBY; MARTIN, 1983). Entre as inúmeras condições presentes no contexto familiar, Bronfenbrenner e Morris (1998), destacam que os padrões de interações entre os membros familiares constituem o principal veículo para a mudança comportamental e o desenvolvimento pessoal dos indivíduos. Ainda afirmam que, as interações que ocorrem entre os sujeitos são caracterizadas pela reciprocidade (o que um indivíduo faz influencia o outro) e pelo afeto (estabelecimento de sentimentos positivos). As primeiras interações, que ocorrem entre os sujeitos, são consideradas uma díade (mãe e criança, pai e criança, entre outros), e proporcionam trocas intersubjetivas que podem promover o desenvolvimento sadio da criança, além de exercer influência sobre os aspectos relativos à aprendizagem escolar.

Nos estudos que priorizaram investigar as relações entre pais e filhos, é possível identificar duas dimensões distintas na interação entre eles, sendo elas as práticas e as crenças parentais (CLAES; LACORSE; BOUCHARD; PERUCCHINI, 2003; GERGIOU; TOURVA, 2007; AGUENA, 2010; FANTINATO; CIA, 2011; PACHECO; MATA, 2013; CIA; BARHAM; FONTAINE, 2012; TONI; HECAVEÍ, 2014). De acordo com Claes, Lacorse, Bouchard e Perucchini 
(2003), as práticas parentais podem ser compreendidas pelas estratégias de comunicação, interação, participação e afetividade (Emocional bolding), supervisão, controle assertivo (Parent supervision) e controle punitivo (Punitiveness). Essas estratégias são utilizadas pelos pais como norteadoras para orientar os filhos. Em relação ao estudo das práticas parentais, é comumente encontrado na literatura o uso de dois tipos de práticas, as indutivas e as coercitivas.

As práticas parentais indutivas sinalizam para a criança a consequência de seus atos, possibilitando para a criança a compreensão das consequências das suas ações. Já as práticas coercitivas se caracterizam pela aplicação direta da força, incluindo a punição física (ALVARENGA; PICCININI, 2009; MARIN; PICCININI; TUDGE, 2011). Essas práticas incluem punição física e privação de privilégios ou ameaças, compelindo a criança a adequar seu comportamento às reações punitivas dos pais. Consequentemente, essas práticas podem provocar emoções intensas, como hostilidade, medo e ansiedade, interferindo na capacidade da criança para ajustar o seu comportamento. As estratégias coercitivas provocam o controle do comportamento firmado na ameaça de sanções externas e intensificam a percepção de valores e do padrão de ação moral como externos, enquanto as estratégias indutivas favorecem a internalização moral (HOFFMAN, 1975).

Para Carvalho e Gomide (2005), as práticas educativas parentais referem-se às estratégias, utilizadas pelos pais, para controlar o comportamento infantil e para desenvolver valores e atitudes positivas em seus filhos, com o objetivo de socialização. É importante ressaltar que ao analisar o contexto de interação familiar, as estratégias e os tipos de práticas utilizadas pelos pais podem ocorrer por influências do contexto imediato, da cultura, da classe social e da composição familiar.

Ainda nesta linha de investigação sobre o contexto familiar, na década de 50, do século passado, foi possível verificar um interesse dos pesquisadores em investigar a influência da família no aprendizado escolar. Contudo, foi somente na década de 60 , quando os estudos passaram a avaliar os aspectos que estão presentes no microssistema familiar, e buscar relações com o desempenho escolar dos alunos, que esses estudos ganharam destaque na literatura. Os primeiros resultados desses trabalhos indicaram que as crianças apresentavam um melhor desempenho escolar quando viviam em um meio familiar, no qual predominava um clima emocional positivo, e seus membros incentivavam, organizavam e reforçavam comportamentos de apoio e incentivo, condições estas que pareciam contribuir com o sucesso escolar dos alunos (MARTURANO, 1999; MUNIZ; SOBEL, 2008; DESSEN, 2010).

Fantinato e Cia (2011), interessados nessas questões, propuseram um estudo para verificar a relação entre a frequência de envolvimento parental, a 
competência social e o desempenho escolar de crianças em idade escolar. As autoras identificaram que quanto maior a frequência de envolvimento, interação e comunicação dos pais com seus filhos, melhor foi o desempenho escolar destes. Além disso, os dados permitiram afirmar que quanto maior a frequência da participação das mães nas atividades escolares, culturais e de lazer dos filhos, menor foi o índice de problemas externalizantes e melhor o repertório de habilidades sociais revelados pelas crianças.

Toni e Hecaveí (2014), numa perspectiva que se diferencia do estudo anterior, se detiveram a investigar a percepção infantil das práticas parentais e analisaram sua relação com o desempenho escolar. As autoras encontraram uma correlação positiva e moderada entre as práticas educativas e o rendimento escolar, principalmente com relação às práticas maternas $(\mathrm{r}=0,404)$. As crianças com alto rendimento escolar perceberam suas mães com maiores níveis de práticas positivas, em comparação às crianças com baixo rendimento. As práticas educativas maternas e paternas foram consideradas preditoras do rendimento escolar dos alunos.

Mais recentemente, outros estudos também têm afirmado que as práticas adotadas pelos pais (envolvimento familiar, afetividade, comunicação) têm um efeito importante no desempenho escolar, na motivação, no autoconceito dos alunos (MARTINELLI; AGUENA, 2011; CIA; BARHAM; FONTAINE, 2012), entre outras variáveis. Para as autoras, as estratégias utilizadas pelos pais, na educação dos filhos, podem influenciar o processo de aprendizagem escolar tanto positiva quanto negativamente.

Seguindo nesta linha de raciocínio, estudos também têm afirmado que as crenças parentais assumem um papel importante nos estudos que envolvem o desenvolvimento e a aprendizagem das crianças. As crenças parentais podem ser definidas como um conjunto organizado de expectativas que resulta tanto da interação entre pais e filhos quanto da cultura acumulada no grupo social de referência familiar (GOODNOW; COLLINS, 1990). Dretske (1983) acrescenta que a crença se relaciona ao processo de acreditar, sendo considerada como uma forma de expressar algo que se encontra no íntimo do pensamento do sujeito.

Dessa forma, com base nas definições de Dretske (1983) e Goodnow e Collins (1990) podemos considerar que o sistema de crenças parentais pode ser entendido como um recurso (compreensão subjetiva) utilizado pelos pais para formar conceitos sobre distintos aspectos que envolvem a vida infantil. Essas crenças são configuradas em um conjunto organizado de expectativas e valores, que estão implícitos nos julgamentos, nas escolhas e nas ações que os pais adotam em relação aos seus filhos. Para Goodnow e Collins (1990), as crenças parentais são fontes de informação importantes que determinam as atitudes e os comportamentos dos pais. 
Por sua vez, Santos e Moreira (2012) entendem que, as crenças parentais estão implícitas nas ações do dia a dia e nas interações entre pais e filhos. As crenças que os pais têm acerca dos seus filhos são concebidas com base na interpretação dos pais mediante a realidade em que estão inseridos, ou seja, formam um conjunto organizado de expectativas acerca da criança, que são compartilhadas com o modelo cultural do qual vivenciam as famílias. Essas crenças funcionam como motivação para a tomada de decisão e para o modelo comportamental adotado pelos pais. Entretanto, conforme afirmam Pollock e Gillies (2000), não é possível considerar que as crenças parentais sejam estáticas, o que significa dizer que os valores e as expectativas dos pais podem ser modificados, uma vez que sofrem a influência do meio externo e também das mudanças que ocorrem na vida de cada indivíduo, pertencente ao grupo familiar.

Diante das colocações acima, pode-se inferir que, pais que são guiados por crenças e expectativas mais positivas em relação ao comportamento e ao potencial dos seus filhos têm mais possibilidades de adotar comportamentos que sejam encorajadores e que expressem confiança, o que por sua vez pode gerar uma condição de maior apoio e incentivo para as crianças. Assim, é possível dizer que existe uma rede de ligação entre as crenças e as práticas parentais.

De acordo com Kobarg e Vieira (2008), as práticas parentais estão fundamentadas no que os pais acreditam ser bom ou ruim para as crianças, no que valorizam (crenças positivas), ou desvalorizam (crenças negativas). Nesse sentido, considera-se que pais que acreditam na importância das suas atitudes para orientar o comportamento das crianças, geralmente, adotam práticas indutivas, que visam promover o desenvolvimento infantil. Por outro lado, pais que não acreditam na importância das suas atitudes, e na capacidade de seus descendentes, supondo que as crianças não precisam de orientação ou que não são capazes de aprender, podem demonstrar práticas mais coercitivas e indiferença em relação aos filhos.

$\mathrm{Na}$ tentativa de verificar as relações entre crenças parentais e desempenho escolar, Gergiou e Tourva (2007) se propuseram a examinar a relação entre as atribuições feitas por pais $(\mathrm{N}=313)$, de alunos que cursavam o ensino médio, em relação ao desempenho de seus filhos; as crenças que apresentavam sobre seu envolvimento no processo educacional das crianças e seu comportamento real em relação a esse envolvimento. Os pais responderam a uma escala de atribuições parentais que avaliava as atribuições em relação à capacidade e ao esforço da criança, família, pais e professores.

A escala de envolvimento parental avaliava as atividades que os pais fazem em casa em relação ao seu filho e com relação à escolarização. Também tiveram que indicar em que grau eles acreditavam que os pais em geral, e eles pessoalmente, como pais, deveriam se envolver nos assuntos educacionais de 
seus filhos. Os resultados revelaram que atribuir a realização a fatores internos e controláveis, como o próprio esforço dos pais, influenciou positivamente a força da crença de "se envolver". Isso, por sua vez, teve um forte efeito sobre a atividade real de envolvimento dos pais.

No estudo realizado por Pacheco e Mata (2013), os autores tiveram por objetivos caracterizar as crenças dos pais sobre a alfabetização e sobre o seu papel nesse processo; analisar as relações entre os vários tipos de crenças dos pais e também entre estas e as práticas de alfabetização do meio familiar. Participaram desse estudo 198 pais de crianças, as quais frequentavam o último ano da educação infantil. Para a coleta de dados, foi usado um um questionário que avaliava quatro componentes diferentes: (1) práticas de alfabetização na família, (2) crenças sobre o processo de preparação para a alfabetização, (3) crenças no papel dos pais nesse processo de alfabetização; (4) ambientes de leitura e escrita. Para coleta de dados foi utilizado um questionário que incluiu a caracterização dos quatro componentes diferentes: (1) práticas de letramento família, (2) crenças no processo de aprendizagem sobre a alfabetização de preparação, (3) o papel de crenças sobre os pais de preparação em alfabetização; (4) o meio ambiente na alfabetização. Como resultados principais, os autores identificaram que as práticas de Ensino e Treino foram as referidas como mais regulares seguidas das práticas de Entretenimento e, por último, as do dia a dia. No que se refere às crenças, pode-se identificar que os pais valorizavam o seu papel na leitura de histórias e no ensino de práticas contextualizadas. Ao realizarem uma análise de cluster foi possível identificar três grupos de pais, com características distintas, quer nas práticas educativas de alfabetização, quer nas suas crenças. Os autores concluíram pela não existência de uma associação linear entre crenças e práticas uma vez que, pais em grupos distintos apresentavam concepções semelhantes em alguns aspectos.

Embora a literatura venha apontando, já há algum tempo, a relevância em se conduzir estudos voltados para a análise do contexto familiar, pode-se considerar que a pesquisa neste campo avançou pouco e, menos ainda quando se trata de estudos que forneçam dados empíricos a esta área de conhecimento. Considerando-se a importância da temática exposta, e do fato de que ainda não há um consenso entre os estudos realizados sobre as relações entre práticas, crenças parentais e desempenho escolar, o presente estudo foi conduzido.

Dados empíricos que possam contribuir com a análise e discussão das variáveis citadas acima podem ser fontes importantes de informação. Portanto, objetivou-se neste estudo analisar as possíveis relações entre o desempenho em escrita de estudantes do ensino fundamental com as práticas e crenças declaradas pelos pais e investigar as relações entre as práticas e crenças parentais. 
Nesta investigação, as práticas parentais foram avaliadas pelo uso das estratégias de comunicação e participação dos pais. A comunicação entre pais e filhos é estabelecida quando os pais transmitem mensagens educativas para seus filhos, e também, quando recebem as mensagens que as crianças expressam, com o intuito de compreender e aceitar opiniões divergentes. A participação relacionou-se intimamente com a presença dos pais nas atividades escolares que a criança realiza, bem como com a supervisão do comportamento dos seus filhos. Por sua vez, as crenças foram avaliadas considerando dois importantes aspectos e referentes às expectativas dos pais, ou seja, quanto à crença na capacidade das crianças e na sua conduta social.

\section{Método}

\section{Participantes}

A amostra deste estudo contou com 446 alunos, e seus respectivos pais, de ambos os gêneros, que cursavam os $2^{\circ}(22,4 \%), 3^{\circ}(27,4 \%), 4^{\circ}(26,7 \%)$ e $5^{\circ}(23,5 \%)$ anos do ensino fundamental, de quatro escolas da rede estadual de ensino, de uma cidade do interior do estado de São Paulo. Os alunos apresentaram a idade média de nove anos, com desvio-padrão de 1,15 , variando entre sete e onze anos, sendo 252 (56,5\%) do gênero feminino e 194 (43,5\%) do gênero masculino. Os pais apresentaram a idade média de 35 anos, com desvio-padrão de 7,68, variando entre 19 a 69 anos, sendo que, as mães representaram 87,7\% dos participantes e os pais $12,3 \%$.

\section{Instrumentos}

Inventário de Práticas e Crenças Parentais - IPCp (MARTINELLI; AGUENA MATSUOKA; FERNANDES, 2017). O IPCp é um inventário que propõe avaliar as práticas e crenças dos pais para com os seus filhos, com base em dois fatores denominados, Envolvimento parental na rotina da criança (6 itens) e Crenças dos pais na capacidade e conduta dos filhos (9 itens). O primeiro fator deste inventário está relacionado com as práticas de comunicação e participação dos pais, cujo principal objetivo é verificar se os pais conversam e se participam das atividades que seu filho realiza. Já o segundo fator tem o objetivo de verificar os tipos de crenças que os pais apresentam com relação ao desempenho escolar e a conduta social dos seus filhos.

Os itens dos dois fatores do inventário estão dispostos na forma de autoinforme, com um total de 15 itens. Cada item apresenta três opções de resposta 
(sempre, às vezes e nunca). A pontuação dos itens foi de dois pontos para a resposta sempre, um ponto para às vezes e zero para nunca. Essa pontuação teve seu valor invertido para os itens escritos na negativa. Dessa forma, quanto maior a pontuação dos pais, mais alta é a frequência das práticas e crenças declaradas por eles, sendo a pontuação máxima de 30 pontos. Os coeficientes de consistência interna dos fatores foram calculados, e os valores do coeficiente de Alfa de Cronbach foram de 0,820 para o fator 1 (Envolvimento parental na rotina da criança) e 0,788 para o fator 2 (Crenças dos pais na capacidade e conduta dos filhos). Como exemplos de itens desta escala, pode citar para o fator 1: Eu trabalho muito e não consigo acompanhar o que meu filho faz na escola, e para o fator 2: Eu acho que meu filho é responsável.

\section{Teste de Avaliação da Escrita - TAE}

OTAE (MARTINELLI; CALIATTO; FERREIRA; CONCEIÇÃO; AGUENA MATSUOKA, 2015) é um instrumento de avaliação da escrita proposto para alunos do Ensino Fundamental e tem como objetivo avaliar as habilidades de codificação e de composição escrita dos alunos. A elaboração desse instrumento foi realizada com base em uma história que se passa num dia de aula regular na escola e que é transmitida para os alunos por meio de um vídeo, com duração de aproximadamente quatro minutos. Esse vídeo é apresentado para os estudantes no início do teste. Com base nos elementos presentes na história infantil, são propostas as atividades de escrita do instrumento que é composto de seis subtestes, iniciando pela escrita de sílabas até a composição de um texto criativo. O subteste de escrita contempla 17 sílabas (Ex: ta, cas, lhões, guas, fi, dei), seguido de um ditado de 25 palavras (Ex: sala, mochila, roupa, gargalhada, carteira) e um ditado de 17 pseudopalavras (quentico, lequipa, teneda, gutapoca, forinfura). No quarto subteste, os alunos devem escrever frases que lhe são ditadas, num total de seis (Ex: Os alunos gostaram da atividade, A aula mais interessante aconteceu no pátio da escola. Uma caixa misteriosa foi apresentada! Ao verem a caixa aberta, as crianças reagiram com: espanto, desagrado, alegria e euforia). O quinto e sexto subtestes são destinados à composição escrita. No subteste 5 é solicitada a escrita de três frases, cada uma delas com base em uma cena da história (vídeo) e, no último subteste, a partir de uma ilustração que corresponde à cena final da história apresentada é solicitada a escrita de um breve texto sobre o final dessa história. Para o presente trabalho foram utilizados os subtestes de 1 a 4 . Para a correção dos subtestes, atribui-se um ponto para cada acerto e 0 para erro. 
Análises iniciais do instrumento (RASCH, 1960) indicaram que as informações psicométricas obtidas dos subtestes de ditado de sílabas, palavras e pseudopalavras foram satisfatórias e permitem o seu uso para a avaliação das crianças (FERNANDES; MARTINELLI, 2017). Nesse sentido, para o subteste de sílabas obteve-se um média de infit de 1,00 e de outfit de 1,06, considerados índices de ajuste adequados (LINACRE, 2009). O índice mais elevado de infit foi 1,23 e do outfit foi 1,67, sendo que nenhum deles representa um desajuste preocupante. O índice de Reliability foi muito alto, 0,99. O subteste de palavras também apresentou resultados satisfatórios. A média do infit foi $1,00(\mathrm{DP}=0,13)$ e do outfit foi $1,25(\mathrm{DP}=1,05)$. O item com maior infit obteve 1,40 e com o maior outfit 6,25 . Esse valor de outfit é preocupante, por isso foi realizada uma análise de ajuste individualizada para cada item. Observou-se que esse item se refere à palavra bola e foi o único que apresentou um desajuste severo, o que indica que crianças com uma habilidade alta erraram a escrita dessa palavra, o que provocou tal desajuste. Finalmente, o índice de Reliability foi 0,99. No caso do subteste de pseudopalavras, as médias do infit e do outfit dos itens foram, respectivamente, $1,00(\mathrm{DP}=0,8)$ e $0,97(\mathrm{DP}=0,12)$. O infit mínimo foi 0,84 e o máximo, 1,14 . Os valores de outfit variaram de 0,70 a 1,21. O índice de Reliability foi 0,98. Todos os indicadores desse subteste também foram satisfatórios.

\section{Procedimento de coleta de dados}

O presente estudo foi realizado após parecer favorável do Comitê de Ética e Pesquisa (parecer $n^{\circ} 1.179 .079$ ). Todos os procedimentos éticos de pesquisa foram levados em consideração. Os participantes foram contatados na reunião bimestral de pais realizada pelas escolas. Na oportunidade foram apresentados os objetivos do estudo e a observância da livre participação, caso os pais não quisessem ou não se sentissem à vontade para participar, sem prejuízo aos pais e aos filhos. Parte dos pais respondeu ao instrumento (IPCp) na própria escola, em sala reservada, após o término da reunião pedagógica. Aos pais que não estavam presentes na reunião foi enviado um convite para participar da pesquisa e os que aceitaram responderam ao IPCp em sua residência, devolvendo o instrumento para a escola por meio da agenda do aluno. O TAE foi aplicado de forma coletiva, em sala de aula, com grupos de alunos divididos de acordo com o ano escolar. O tempo médio de aplicação foi de 50 minutos, sendo que, para os alunos mais novos ( $2^{\circ}$ ano) o tempo médio de aplicação foi de 65 a 75 minutos. 


\section{Resultados}

As análises indicaram uma correlação significante e positiva entre o desempenho em escrita dos alunos (sílabas, palavras, pseudopalavras) e as práticas e crenças declaradas pelos pais. A Tabela 1 apresenta os resultados da correlação entre as práticas e crenças parentais com o desempenho em escrita dos alunos do segundo, terceiro, quarto e quinto ano escolar, obtido por meio do Teste de Avaliação da Escrita (TAE).

TABELA 1 -CORRELAÇÕES ENTRE O DESEMPENHO EM ESCRITAE PRÁTICAS E CRENÇAS PARENTAIS

\begin{tabular}{lcc}
\hline IPCp & \multicolumn{2}{c}{ Desempenho em escrita } \\
\hline & $\mathrm{r}$ & $\mathrm{p}$ \\
F1- Envolvimento parental na rotina da criança & 0,77 & 0,107 \\
F2- Crenças dos pais na capacidade e conduta dos filhos & $0,223^{* *}$ & $<0,01$ \\
Total & $0,182^{* *}$ & $<0,01$ \\
\hline
\end{tabular}

** correlação significante ao nível de 0,01

FONTE: As autoras, 2017.

Na Tabela 1, observa-se que houve uma correlação significante e positiva entre o fator relativo às crenças parentais e o IPCp total com o desempenho em escrita. Esse resultado revelou que, quando os pais declararam apresentar uma maior frequência de crenças positivas, seus filhos apresentaram um melhor desempenho na escrita. Com o intuito de imprimir um olhar qualitativo sobre os dados, realizou-se uma análise mais pontual sobre o desempenho dos alunos $\left(2^{\circ}, 3^{\circ}, 4^{\circ}\right.$ e $5^{\circ}$ ano $)$ e os itens do fator de crenças parentais. A Tabela 2 apresenta os coeficientes de correlação entre os itens do fator relativo às crenças com o desempenho geral em escrita dos alunos.

TABELA 2 - CORRELAÇÕES ENTRE O DESEMPENHO GERAL EM ESCRITA (SÍLABAS, PALAVRAS E PSEUDOPALAVRAS) E OS ITENS DO FATOR CRENÇAS PARENTAIS

\begin{tabular}{lcc}
\hline IPCp & $\mathbf{r}$ & $\mathbf{p}$ \\
\hline F2. Eu acho que meu filho é um bom aluno & $0,326^{* *}$ & $<0,01$ \\
F2. Eu acho que meu filho é responsável & $0,174^{* *}$ & $<0,01$ \\
F2. Eu acho que meu filho é um bom filho & $0,117^{*}$ & 0,014 \\
F2. Eu acredito que meu filho está indo bem na escola & $0,306^{* *}$ & $<0,01$ \\
\hline
\end{tabular}

Nota: ${ }^{* *}$ correlação significante ao nível de 0,$01 ;{ }^{*}$ correlação significante ao nível de 0,05 FONTE: As autoras, 2017. 
Na Tabela 2, observa-se uma correlação significativa entre quatro das nove afirmativas, relativas ao fator de crenças parentais, com o desempenho em escrita (sílabas, palavras e pseudopalavras). Embora os coeficientes de correlação não tenham sido fortes foi possível verificar que foram os itens, "Eu acho que meu filho é um bom aluno" e "Eu acredito que meu filho está indo bem na escola", relativos às crenças parentais relacionadas à escola, que tiveram um índice de correlação mais forte.

Por sua vez, a análise das relações entre as subescalas de práticas e crenças parentais revelou a existência de correlação positiva entre elas, embora de magnitude muito fraca $(\mathrm{r}=0,134$ e $\mathrm{p}=0,05)$.

\section{Discussão e considerações finais}

Embora seja importante pontuar que a pesquisa que envolve variáveis familiares e educacionais ainda esteja no seu início, é possível dizer que é uma área que vem ganhando espaço nos últimos anos, e tem aberto novos campos de investigação. Conforme apontam Pacheco e Mata (2013), parece importante continuar a considerar o papel desempenhado pelas práticas e crenças dos pais no processo de escolarização de estudantes. Esta foi a linha de investigação adotada no presente estudo, que buscou investigar as relações entre práticas e crenças parentais e o desempenho em escrita de alunos do ensino fundamental. Os resultados encontrados permitiram comprovar apenas em parte esta relação, uma vez que o fator relativo às práticas parentais não se correlacionou com o desempenho dos alunos, contrariamente aos achados do estudo de Toni e Hecaveí, 2014. No entanto, é importante salientar que neste estudo as práticas investigadas não estavam diretamente relacionadas com a atividade de escrita ou voltadas à supervisão e práticas de ensino, como investigado pelos autores, mas tratavam de práticas gerais adotadas pelos pais em relação à comunicação que mantinham com seus filhos e a participação destes na rotina da criança.

Por outro lado, pode-se verificar a existência de uma correlação positiva e significante entre a declaração dos pais sobre suas crenças na conduta e comportamento dos filhos, e um melhor desempenho destes na avaliação escrita que foi conduzida. Esses resultados corroboraram com os estudos de Georgiou e Tourva, (2007); Aguena, (2010); Pacheco e Mata, 2013. Importante destacar que os itens que revelaram uma correlação mais forte com o desempenho estavam relacionados às crenças dos pais quanto à capacidade de seus filhos enquanto alunos. 
Estes dados, somado ao de outros estudos, que também trataram de variáveis parentais, nos permitem algumas reflexões. Apesar das relações encontradas nestes estudos, e da literatura indicar uma relação positiva entre práticas, crenças e desempenho escolar, é importante destacar que ainda não é possível afirmar sobre a característica preditora, de uma destas variáveis, sobre o desempenho de alunos, uma vez que os estudos não têm proposto modelos de análise que permitam comprovar essas relações. A relevância do tema sugere que novas pesquisas sejam realizadas e busquem ampliar as análises já conduzidas em estudos anteriores.

Entre as análises a serem conduzidas, parece ser importante determinar que tipo de práticas efetivamente contribuem com o desempenho. Os instrumentos têm priorizado aspectos muito distintos em suas avaliações, entre eles práticas mais de cunho geral como de rejeição, castigo físico, apoio, receptividade, até práticas mais específicas e relativas ao processo de escolarização como monitoramento, envolvimento com a escolaridade dos filhos, entre outros. O mesmo raciocínio deve ser adotado ao se pensar sobre as crenças. Neste estudo pode-se verificar que, entre os nove itens que compunham o fator relativo às crenças apenas quatro se revelaram correlacionados ao desempenho dos alunos. Entre eles dois se destacaram, exatamente os que estavam relacionados a uma crença escolar. Esse dado aponta para a necessidade de se investigar de forma mais pontual quais seriam de fato as crenças que teriam uma força suficiente para interferir sobre o desempenho.

Outra questão que se coloca diz respeito às relações entre as práticas e crenças parentais. Parece existir uma tendência em apontar as crenças como determinantes das práticas parentais empregadas pelas famílias. Assim, os pensamentos (convicções, valores) dos pais sobre os seus filhos, passam a ser vistos como referência para que sejam desenvolvidas as práticas parentais. Acredita-se que crenças desenvolvidas sobre o que seja bom ou ruim, certo ou errado, entre outras, influenciam as práticas adotadas pelos pais na educação de seus filhos (KOBARG; SACHETTI; VIEIRA, 2006; SANTOS; MOREIRA, 2012). Como poucos estudos investigaram essa direcionalidade e, como as relações ainda não são claras, essa lacuna continua aberta para futuras investigações. No estudo de Pacheco e Mata (2013), por exemplo, os autores não puderam afirmar pela existência de uma associação linear entre crenças e práticas. No estudo conduzido por Martinelli, Aguena Matsuoka e Fernandes (2017), em que investigaram as propriedades psicométricas do instrumento utilizado neste estudo, as autoras verificaram que, embora os itens dos dois fatores representem elementos dos constructos de práticas e de crenças parentais, os resultados do estudo indicaram que, para o conjunto de itens propostos, não houve correlação 
entre os dois fatores, o que indica tratar-se de dois instrumentos ou constructos que funcionam de forma independente. Neste estudo foi verificada uma correlação positiva e fraca entre os dois fatores o que sugere que outras investigações merecem ser conduzidas, considerando a possibilidade de que os constructos sejam trabalhados separadamente.

Por fim, cabe destacar que, embora sejam necessárias mais evidências sobre as relações entre as práticas e o sistema de crenças parentais, bem como destas com o desempenho das crianças em seu percurso escolar, as evidências reveladas até o presente momento, ressaltam a importância de orientações voltadas aos pais. Assim, realizar orientações com o olhar sobre as famílias, em qualquer que seja a forma que esta assuma, pode contribuir na criação de uma rede apoio tanto aos pais ou cuidadores responsáveis, quanto à criança ou ao jovem, o que pode favorecer, entre outros aspectos, os relativos ao desenvolvimento pessoal e escolar desses indivíduos.

Contudo, como apontam Lordelo, Fonseca e Araújo (2000), entre outros, não se pode desconsiderar que a compreensão e a interpretação que os indivíduos, e mais particularmente os pais, têm sobre a realidade, são geradas num contexto, local e tempo específicos, o que torna esse conhecimento fortemente influenciado pela cultura. Dessa forma, qualquer interpretação e proposta de intervenção em uma realidade deve, além de levar em conta as características do grupo, também considerar que esses conhecimentos são mutáveis. Ainda, conforme apontam Kobarg, Sachetti e Vieira (2006), embora a compreensão da relação entre a natureza humana e a cultura seja uma questão complexa, é necessária para a compreensão do comportamento humano.

\section{REFERÊNCIAS}

AGUENA, E. C. As crenças e atitudes parentais e o desempenho escolar de estudantes do ensino fundamental. 2010. Dissertação (Mestrado em Educação) - Universidade Estadual de Campinas, Campinas, 2010.

ALVARENGA, P.; PICCININI, C. A. Práticas educativas maternas e indicadores do desenvolvimento social no terceiro ano de vida. Psicologia: Reflexão e Crítica, v. 22, n. 2, p. 191-199, 2009.

BAUMRIND, D. Effects of authoritative parental control on child behavior. Child Development, v. 37, n. 4, p. 887-907, 1966. 
BRONFENBRENNER, U.; MORRIS, P. The ecology of developmental processes. In: DAMON, W. (Org.). Handbook of child psychology (993-1027). New York: John Willey \& Sons, 1998.

CARVALHO, M. C. N. D.; GOMIDE, P. I. C. Práticas educativas parentais em famílias de adolescentes em conflito com a lei. Estudo de Psicologia, Campinas, v. 22, n. 3, p. 263-275, 2005.

CIA, F.; BARHAM, E. J.; FONTAINE, A. M. G. V. Children's academic performance and self-concept: contributions of father involvement. Estudos de Psicologia, v. 29, n. 4, p. 461-470, 2012.

CLAES, M.; LACOURSE, E.; BOUCHARD, C.; PERUCCHINI, P. Parental practices in late adolescence, a comparison of three countries: Canada, France and Italy. Journal of Adolescence, v. 26, n. 4, p. 387-399, 2003.

DARLING, N.; STEINBERG, L. Parenting Style as Context: an integrative Model. Psychological Bulletin, v. 113, n. 3, p. 487-496, 1993. DOI: http://dx.doi. org/10.1037/0033-2909.113.3.487

DESSEN, M. A. Estudando a Família em desenvolvimento: desafios conceituais e teóricos. Psicologia Ciência e Profissão, v. 30 (spe), p. 202-219, 2010.

DRETSKE, F. I. The epistemology of beliefs. Synthese, v. 55, n. 1, p. 3-19, 1983. DOI: http://dx.doi.org/10.1007/BF00485371

FANTINATO, A. C.; CIA, F. Envolvimento parental, competência social e o desempenho acadêmico de escolares. Psicologia Argumento, v. 29, n. 67, p. 499-511, 2011.

FERNANDES, D. C.; MARTINELLI, S. C. Escrita e ortografia: análise de produções infantis. Revista Psicologia - Teoria e Prática, v. 19, 2017.

GEORGIOU, S. N.; TOURVA, A. Parental attributions and parental involvement. Social Psychology of Education, v. 10, n. 4, p. 473-482, 2007.

GOODNOW, J. J.; COLLINS, W. A. Development according to parents: The nature, sources, and consequences of parents' ideas. New York: Psychology Press, 1990.

HOFFMAN, M. L. Moral, internalization, parental power, and the nature of parent child interaction. Developmental Psychology, v. 11, n. 2, p. 228-239, 1975. DOI: http://dx.doi. org/10.1037/h0076463

KOBARG, A. P. R.; SACHETTI, V. A. R.; VIEIRA, M. L. Valores e crenças parentais: reflexões teóricas. Psicologia: Reflexão e Crítica, v. 16, n. 2, p. 96-102, 2006.

LINACRE, J. M. A user's guide to Winsteps \& Ministeps: Rasch Model computers Programs. Chicago, IL: Winsteps.com., 2009.

LORDELO, E. R.; FONSECA, A. L; ARAÚJO, M. L. V. B. Responsividade do ambiente de desenvolvimento: crenças e práticas como sistema cultural de criação de filhos. Psicologia: Reflexão e Crítica, v. 13, n. 1, p. 73-80, 2000. 
MACCOBY, E. E.; MARTIN, J. A. Socialization in the Context of the Family: ParentChild Interaction. In: MUSSEN, P. H. (Ed.). Handbook of Child Psychology: Formerly Carmichael's Manual of Child Psychology. New York: John Willey \& Sons, 1983.

MARIN, A. H.; PICCININI, C. A.; TUDGE, J. Estabilidade e mudança nas práticas educativas maternas e paternas ao longo dos anos pré-escolares da criança. Psicologia: Reflexão e Crítica, v. 24, n. 1, p. 71-79, 2011.

MARTINELLI, S. C.; CALIATTO, S. G. A família e a criança: considerações sobre a afetividade, as relações sociais e a escolarização. In: MARTINELLI, S. C.; FERNANDES, D. C. (Org.). Aprendizagem escolar na contemporaneidade. Curitiba: Juruá, 2017. p. 53-69.

MARTINELLI, S. C.; AGUENA MATSUOKA, E. C.; FERNANDES, D. C. Estudo Fatorial de um Inventário de Práticas e Crenças Parentais. Psico USF, v. 22, n. 2, p. 249-260, 2017.

MARTINELli, S. C.; CALIATTO, S. G.; FERREIRA, A. A.; CONCEIÇÃO, A. K.; AGUENA-MATSUOKA, E. C. Teste de avaliação da escrita (TAE): proposta de instrumento de avaliação. In: CONGRESO INTERNACIONAL DE EDUCACIÓN Y APRENDIZAJE, 22., Madri: Espanha, 2015.

MARTINELLI, S. C.; AGUENA, E. C. La motivación en estudiantes de enseñanza fundamental y las creencias y actitudes de los padres. Revista de Investigación en Psicología, v. 14, n. 1, p. 53-64, 2011.

MARTURANO, E. M. Recursos no ambiente familiar e dificuldades de aprendizagem na escola. Psicologia: Teoria e Pesquisa, v. 15, n. 2, p. 135-142, 1999.

MUNIZ, A. L. P.; SOBEL, T. F. Características das famílias de crianças trabalhadoras em Minas Gerais em 2004. In: ENCONTRO NACIONAL DE ESTUDOS POPULACIONAIS, 16., ABEP, Caxambu, MG, 2008. Anais... Caxambu, 2008.

PACHECO, P.; MATA, L. Literacia Familiar - crenças dos pais de crianças em idade pré-escolar e características das práticas de literacia na família. Análise Psicológica, v. 31, n. 3, p. 217-234, 2013. DOI:10.14417/S0870-8231201300030001

POLLOCK, J. L.; GILLIES, A. S. Belief revision and epistemology. Synthese, v. 122, n. 1-2, p. 69-92, 2000.

SANTOS, M. P.; MOREIRA, P. A. Desenvolvimento e validação do questionário de avaliação das crenças parentais acerca dos fatores determinantes do rendimento académico dos seus filhos. Journal of Child and Adolescent Psychology, v. 3, n. 1, p. 15-38, 2012.

SANTOS, A. A. A.; MARTINELLI, S. C.; MONTEIRO, R. M. Suportes e recursos familiares: relações com o contexto escolar. In: BAPTISTA, M. N.; TEODORO, M. L. M. (Org.). Psicologia de Família; teoria, avaliação e intervenção. Porto Alegre: Artmed, 2012. p. 137-144. 
SILVA, N. V.; HASENBALG, C. Recursos familiares e transições educacionais. Cadernos de Saúde Pública, v.18 (Suplemento), p. 67-76, 2002. DOI: http://dx.doi.org/10.1590/ S0102-311X2002000700008

TONI, C. G. D. S.; HECAVEÍ, V. A. Relações entre práticas educativas parentais e rendimento acadêmico em crianças. Psico-USF, v. 19, n. 3, p. 511-521, 2014. DOI: http:// dx.doi.org/10.1590/1413-82712014019003

Texto recebido em 03 de agosto de 2017. Texto aprovado em 25 de dezembro de 2017. 